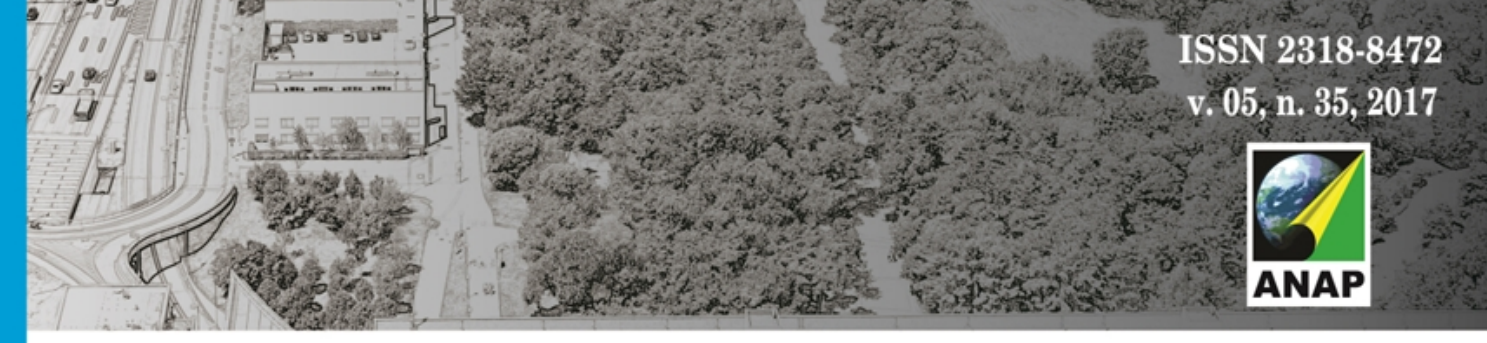

Gerenciamento de Cidades

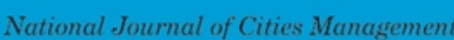

\title{
Marketing de lugares para o gerenciamento de cidades - percepções sobre Cerro Largo/RS
}

\author{
Marketing of places for city management - \\ perceptions about Cerro Largo / RS
}
Marketing de lugares para la gestión de ciudades - percepciones sobre Cerro Largo / RS

\section{Luciana Scherer}

Doutoranda no Programa de Pós Graduação em Desenvolvimento Regional (UNIJUì) lucianascherer@yahoo.com.br

\section{Lurdes Froemming}

Doutora, Professora no Programa de Pós Graduação em Desenvolvimento Regional (UNIJUì) lurdes@unijui.com.br

Sandra Fernandes Doutora, Professora no Programa de Pós Graduação em Desenvolvimento Regional (UNIJUì) sandravf@unijui.edu.br

Louise de Lira Roedel Botelho

Doutora, Professora no Curso de Administração (UFFS)

louise@uffs.edu.br 


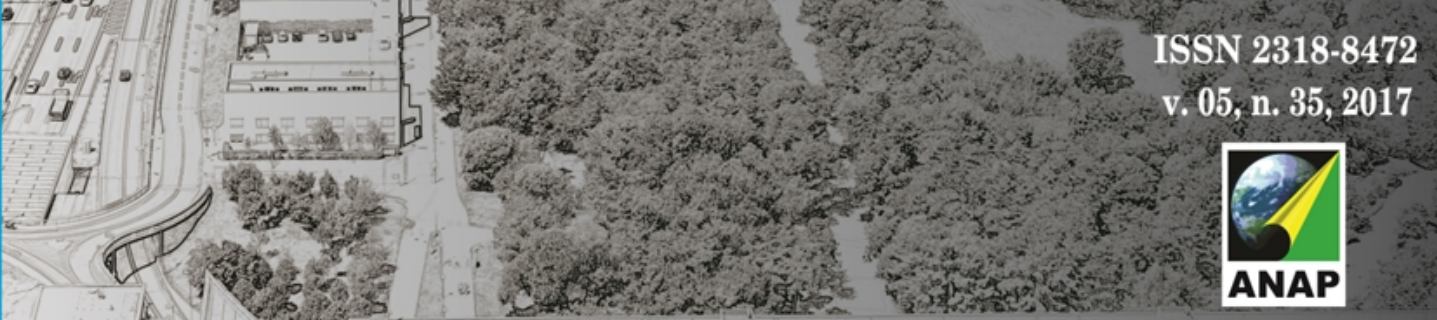

Revista Nacional de

Gerenciamento de Cidades

\section{MARKETING DE LUGARES}

O marketing apresenta uma série de olhares que buscam a sua definição, seus entendimentos, áreas e escopos de tratamento. Análises que buscam evoluções de definições conforme distintos autores (AJZENTAL, 2010), que abordam a "popularização" do termo no Brasil (RICHERS, 2000), que buscam definições sobre o que é marketing e quais as suas possíveis orientações dentro da ciência social aplicada (BAKER, 2005), seu papel no consumo (BARBOSA, 2010), dentre muitas outras abordagens.

Por muito tempo o entendimento na área baseava-se na definição elaborada pela Associação Americana de Marketing, a qual entendia que o marketing abrangia as atividades referentes ao fluxo de bens e serviços entre produtor e consumidor empresariais, porém, a repercussão de alguns movimentos de consumidores levou a um reconhecimento de que marketing não deveria ficar restrito à atuação de empresas privadas. Assim foi surgindo a ampliação do escopo do marketing para abranger áreas como igrejas, hospitais, partidos políticos, desporto, escolas, Estado e serviços públicos (RICHERS, 2000; ALMEIDA, 2004).

Para se entender marketing de lugares, é preciso tentar um entendimento claro do que é marketing, e nesse estudo parte-se da definição de que é um processo social pelo qual indivíduos e grupos obtêm o que necessitam e desejam por meio da criação, da oferta e da livre troca de bens e serviços de valor com outros (KOTLER e KELLER, 2006).

Já marketing de lugares, por sua vez é uma área de aplicação do marketing, considerada um processo contínuo que envolve os cidadãos, seja na esfera pública ou privada em busca do processo de desenvolvimento local na sua comunidade, entendido como os processos sociais e de gestão que são desenvolvidos nos lugares para atender à satisfação de necessidades e desejos de indivíduos e de organizações, considerada por Kotler et al (1994) a forma como o marketing pode ajudar a preparação das cidades para o futuro incerto.

A origem do Marketing de Lugares remonta à Europa na idade colonial, quando jornais locais realizavam propaganda e publicidade das localidades, como forma de ressaltar a imagem e o turismo local; ou às estratégias dos Estados Unidos ao divulgar o país em busca de investimentos em prol da "Construção da América" (MINCIOTTI \& SILVA, 2011), mas em termos de conceito, ganhou notoriedade como marketing de cidades na década de 1980 e foi posteriormente designado por Kotler et al (1994) como marketing de lugares, já que dessa forma não estaria restrito a municipalidade e poderia então, ser aplicado em diversas esferas locais, regionais, estaduais, nacionais e até mesmo supranacionais.

O marketing de lugar é observado a partir de ângulos diversos e há, evidentemente, diferentes pontos de vista e abordagens na literatura devido a seu caráter multidisciplinar. Ao tratar-se sobre esse campo de conhecimento há que considerar que os conceitos e estado da arte dessa área ainda não estão consolidados (OCKE \& IKEDA, 2014), sendo que na literatura acadêmica o tema pode ser apresentado como marketing territorial, marketing geográfico, marketing público, marketing urbano, marketing de localidade, marketing de cidades, marketing de destinos, marketing turístico (ALMEIDA, 2004; KOTLER, 2006, SCHULER \& PADOIM, 2016), entretanto, independente a terminologia há uma convergência nos significados, que estão relacionados à aplicação do conceito do processo de troca entre cidade, região, estado ou país com os moradores locais, 


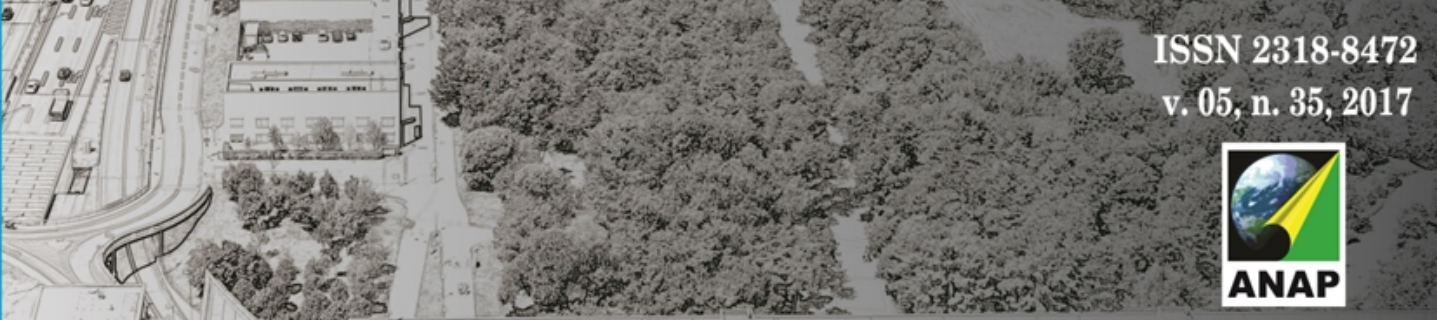

Revista Nacional de

Gerenciamento de Cidades

trabalhadores, estudantes, visitantes, enfim, consumidores - ou clientes - organizações e investidores que tem o intuito de gerar valor às partes envolvidas - ou seja, os stakeholders do lugar.

Na busca de uma sistematização de estudos e abordagens sobre Marketing de Lugares Ocke \& Ikeda (2014) propõe a divisão da área em três perspectivas, que podem também ser consideradas etapas de utilização dos conceitos e ferramentas: a perspectiva promocional, a perspectiva de planejamento e a perspectiva de marca. A perspectiva promocional do marketing de lugares é composta pela orientação de descrever os aspectos da atividade promocional como uma ferramenta para a comercialização de cidades. Em relação a perspectiva de planejamento, a visão dos especialistas parte para um esquema mais ampliado de técnicas e incorporaram a suas ações de administração pública, estratégias mais sofisticadas de marketing tendo como objetivo atingir públicos-alvo específicos e fazendo com que os recursos da comunidade pudessem responder às necessidades e aos desejos dos públicos de interesse em mercados competitivos, ou seja é uma visão onde, a partir do planejamento, utilizando ferramentas de marketing e de administração pública, os lugares buscam diferenciar-se de forma competitiva. E por ultimo, a perspectiva de marca envolve aspectos de seleção, diferenciação e qualificação dos atributos que compõem a marca de um lugar, bem como a participação de diferentes atores no gerenciamento dessa marca e a diversidade de mercados-alvo que representam múltiplas esferas de atratividade para uma localidade. Essas três perspectivas, não apresentam necessariamente uma ordem cronológica, e tampouco delimitações e diferenciações claramente definidas, sendo que coexistem e podem agir de forma complementar entre uma e outra visando à qualificação dos territórios onde serão aplicados.

Outra maneira de analisar os estudos e abordagens de Marketing de Lugares é evidenciada por Kotler et al (1994), onde são listadas as abordagens consagradas para se tratar do desenvolvimento local com vistas ao planejamento e construção de lugares pela perspectiva do marketing: desenvolvimento comunitário, design urbano, planejamento urbano, desenvolvimento econômico e planejamento estratégico de marketing. Cada uma delas utiliza uma filosofia e um enfoque diferente do problema de criar e manter comunidades viáveis.

O desenvolvimento comunitário relaciona-se com a importância de se criar um ambiente de qualidade para as pessoas que moram e/ou trabalham no local que se pretende desenvolver. Para isso, parte-se da necessidade de instalação de boas escolas, vizinhanças participativas e receptivas, maior segurança pública e instalações de saúde - médicos, postos de saúde e hospitais adequados, promovendo o papel de instituições comunitárias sólidas na qualidade de vida de um local, sendo que ao mesmo tempo em que os serviços devem apresentar bom desempenho, o custo deles não deve ser superior ao que o público mostra-se disposto a pagar. Esse construto está bastante ligado à ideia da participação das pessoas no âmbito de seus bairros de atuação, e posteriormente evoluiu como um conceito a ser aplicado ao desenvolvimento urbano geral.

O conceito de design urbano está ligado ao de desenvolvimento comunitário e prega que um local para ter qualidade deve ser um local agradável de viver, sendo que a diferença está naquilo que o local deve priorizar para ser considerado um local de bem viver, ou seja, nas qualidades do design de um lugar: a arquitetura, os espaços ao ar livre e a utilização da terra, o layout das ruas e o fluxo do tráfego, a limpeza e a qualidade ambientais, nas instituições comunitárias e nas pessoas. Segundo essa perspectiva, locais com alta densidade de congestionamento no trânsito, falta de locais de estacionamento, poluição do ar, espaço urbano degradado e assim por diante, são entraves ao melhor planejamento urbano. 


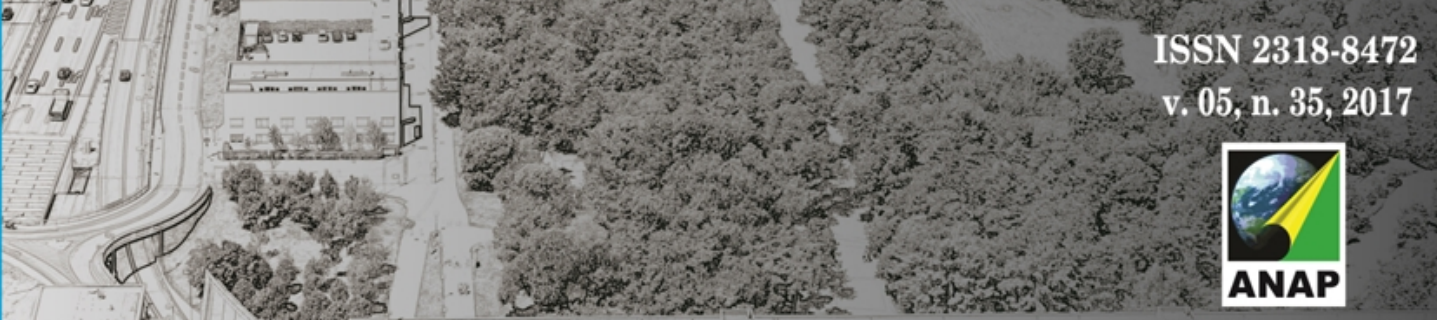

Revista Nacional de

Gerenciamento de Cidades

O Planejamento urbano é entendido como uma unidade, geralmente formada por uma comissão de pessoas, responsável pela avaliação dos diversos projetos propostos pelos órgãos governamentais, com o intuito de discutir o impacto do custo/benefício dessas propostas, e recomendar os melhores investimentos de acordo com as condições orçamentárias da localidade. Geralmente as comissões de planejamento urbano defendem interesses públicos e costumam desempenhar um papel positivo na maioria das localidades.

Embora o desenvolvimento econômico, muitas vezes seja utilizado como sinônimo de crescimento econômico, deve ser entendido como uma etapa mais avançada e qualificada que os locais devem buscar, portanto, desenvolvimento é um conceito que vai além do crescimento. Enquanto o crescimento econômico pressupõe o aumento da produção, o que também aumenta o número de empregos, pessoas e impactos (como congestionamentos e poluição), o desenvolvimento sugere não só mais produtos, como também um leque maior de produtos, novas indústrias, maior utilização produtiva, multiplicidade de recursos de recursos e novas inovações diversificadas.

Por fim, o planejamento estratégico de marketing diz respeito à utilização de técnicas de planejamento estratégico de marketing de empresas nas localidades. Kotler el al (1994) dividem o planejamento estratégico de marketing de localidades em três etapas: Na primeira fase, que tem início nos anos 30 e perdura até os anos 70, o Estado realizava esforços agressivos para atrair negócios e fábricas, sendo que os diferenciais eram mão-de-obra barata, baixos impostos e financiamento público, pautados para atrair novos investimentos para os locais. Já a segunda etapa, entre os anos 70 e 80, volta-se para o Marketing-alvo, e caracteriza-se pelo foco em vários objetivos: manter os negócios sem deixar de atrair novos, desenvolver o turismo, promover exportações e investimentos estrangeiros. As estratégias eram mais elaboradas e refinadas, baseadas em estudo da concorrência e do posicionamento do mercado. Houve assim, a troca do marketing de massa para o marketing especializado, onde os locais aprenderam a segmentar mercados e compradores, baseados em pesquisas e análises com um olhar voltado para a qualidade de vida. Já a terceira fase, ocorrida a partir da década de 90 , caracteriza-se pelo desenvolvimento do lugar como produto, pois as localidades procuraram se definir como lugares diferenciados com vantagens competitivas específicas para as indústriasalvo. Desenvolveu-se o conceito de nicho de mercado, criando-se valores para os clientes-alvo. Investiu-se na manutenção e expansão das organizações empresariais já existentes, e na melhoria da educação dos cidadãos para que funcionassem eficientemente numa sociedade de alta tecnologia e de informações que refletem o desenvolvimento da competição entre locais numa economia mundial que está mudando continuamente. A qualidade de vida passou a ter significativa importância e fatores como receptividade da comunidade local, ambiente intelectual, e incentivo ao empreendedorismo se tornaram atrativos importantes. Devido às pressões da concorrência e da política interna, os locais passaram a encarar suas atividades operacionais de forma mais comercial e competitiva, voltando-se para o mercado, tanto como uma estratégia exógena como endógena do desenvolvimento local.

Assim, na tarefa de planejar o seu futuro, as localidades podem melhorar seus resultados utilizando abordagens consagradas do desenvolvimento de um local, as quais podem ser utilizadas de forma combinada, já que apenas com uma perspectiva de design urbano, ou apenas de desenvolvimento comunitário, por exemplo dificilmente seria possível alcançar o desenvolvimento local de forma plena.

Outra questão importante, dentro da perspectiva de um planejamento estratégico de lugar é identificar os públicos - os clientes a quem se destina o valor da localidade. Minciotti \& Silva (2011) propõem uma divisão 


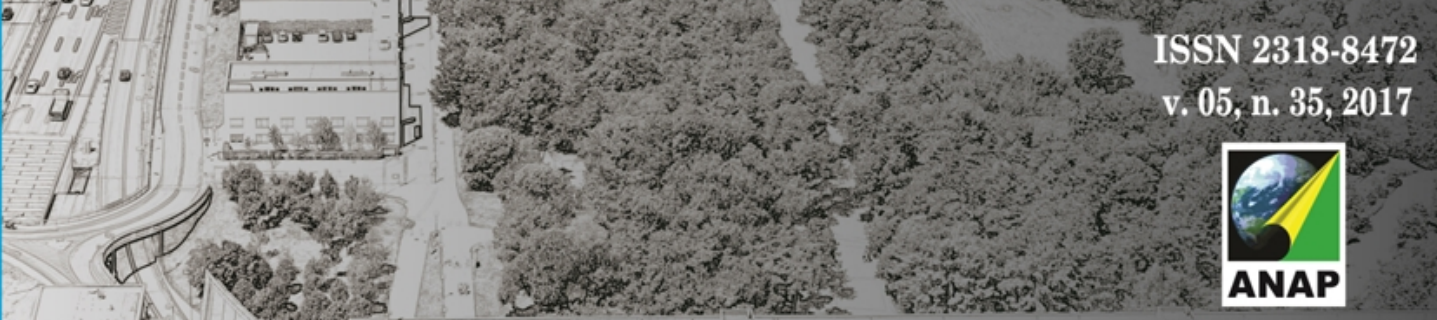

Revista Nacional de

Gerenciamento de Cidades

comunitário, design urbano, planejamento urbano, desenvolvimento econômico e planejamento estratégico de marketing, sendo que cada uma delas utiliza uma filosofia e um enfoque diferente do problema de criar e manter comunidades viáveis, mas podem ser globalmente integradas para a busca de conhecimento de aspectos importantes sobre cidades.

O estilo da pesquisa é de caráter quantitativo, com variáveis nominais e ordinais. Na elaboração do questionário, os públicos a serem investigados basearam-se na proposta de Kotler el al (2006: 186), no qual define sete amplos grupos (Moradores, Visitantes, Gerências, Investidores, Empreendedores, Investidores Estrangeiros e Especialistas de Lugares), conforme apresentado na sessão anterior, e foram adaptados para o interesse da pesquisa e em função da natureza do lugar, e elencados como Moradores, Estudantes, Trabalhadores, Investidores e Visitantes. O público "estudante" foi inserido na pesquisa em função do fato de Cerro Largo possuir um campus de uma Universidade Federal e uma Universidade Privada, portanto, faz-se importante mensurar as percepções específicas desse público - que pode ou não ser morador - e verificar se possui demandas e olhares distintos dos demais. O público "gerências" foi destacado como trabalhador, com o intuito de ampliar o escopo de pesquisa e propiciar uma visão que englobe mais níveis das hierarquias as organizações - esse podendo ser morador da cidade de Cerro Largo, ou morador de outra cidade, mas que certamente impacta a economia e a sociedade com suas relações e portanto, interessa a essa pesquisa. 0 público "empreendedores" foi considerado no universo dos investidores. O público de especialistas em marketing de lugares foi suprimido pelo fato de não haver um universo passível de ser pesquisado na cidade. Poderá ser desenvolvido em pesquisa posterior, com o olhar de especialistas externos acerca da cidade de Cerro Largo. Em relação a investidores estrangeiros, julga-se que não faz parte do escopo da pesquisa, portanto também fora retirado das opções de classificação do público.

Na definição da metodologia de aplicação do questionário estabeleceu-se que as pessoas, em um determinado lugar ou município podem desempenhar diferentes papéis ou personagens, já que podem ser morador, estudante, trabalhador e/ou investidor no lugar. O quinto papel, e esse é excludente, é o de visitante. Assim, cada respondente poderia escolher sobre qual papel gostaria de opinar, e se gostaria de opinar sobre mais de um que o identifica na cidade. Por exemplo, o morador pode trabalhar no lugar pesquisado ou não. Se trabalha e mora na cidade de Cerro Largo, poderia responder nas duas colunas, ou apenas naquela que identifica-se melhor. Assim sucessivamente com os demais papeis morador e estudante; morador e trabalhador, morador e investidor, somente trabalhador, somente visitante ou até mesmo morador e estudante e trabalhador e investidor.

O universo de pesquisa deu-se na cidade de Cerro Largo, por meio de uma amostra não probabilística por conveniência com 200 respondentes e os dados foram tabulados e organizados através do software Microsoft Excel.

\section{RESULTADOS E DISCUSSÕES - UM OLHAR SOBRE CERRO LARGO /RS}

A amostra total desse trabalho, de 200 pessoas, residentes na cidade de Cerro Largo/RS ou em municípios da região, mas que desempenham papéis sócio-econômicos em Cerro Largo (como estudantes, trabalhadores, 


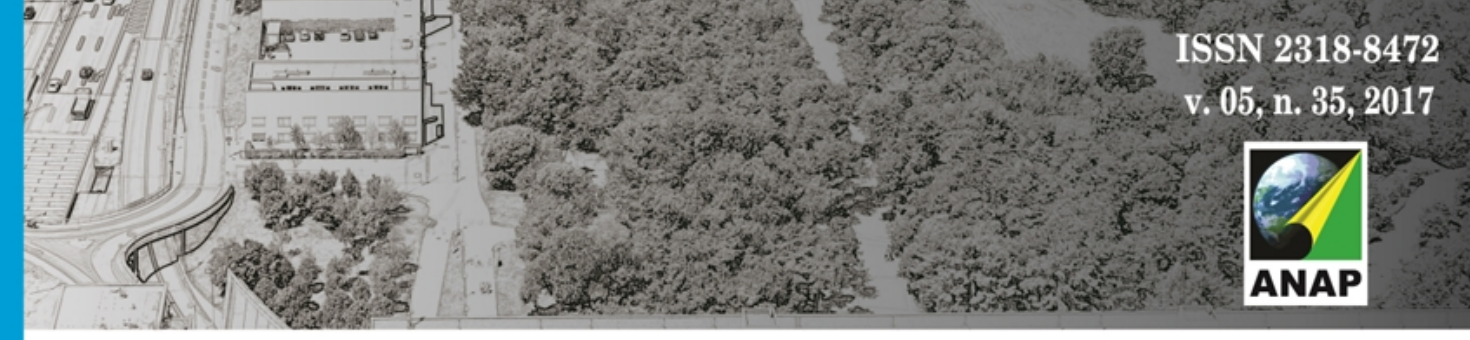

Gerenciamento de Cidades

investidores e/ou visitantes), considerados, para fins dessa pesquisa, stakeholders desse município, conforme tabela 1:

Tabela 1 - Cidade de residência dos respondentes

\begin{tabular}{lr}
\hline \multicolumn{1}{c}{ CIDADE } & No. \\
\hline Cerro Largo & 148 \\
São Pedro do Butiá & 7 \\
Salvador das Missões & 6 \\
Santo Ângelo & 4 \\
Campina das Missões & 4 \\
Guarani das Missões & 4 \\
São Luiz Gonzaga & 3 \\
Santa Rosa & 3 \\
Roque Gonzales & 3 \\
Mato Queimado & 3 \\
Rolador & 3 \\
São Paulo das Missões & 2 \\
Porto Xavier & 2 \\
Candido Godói & 2 \\
Não Informado & 6 \\
\hline
\end{tabular}

Fonte: elaborado pelas autoras

Dos 148 residentes no município, 69\% moram pelo menos há mais de 10 anos no município de Cerro Largo, sendo que $47 \%$ que sempre residiram e $22 \%$ moram há mais de 10 anos, o que traz uma maior consistência nas respostas, já que quanto maior o tempo no município, maior o envolvimento e pressupõe-se um maior conhecimento acerca das características necessárias para uma boa percepção do município.

As ocupações profissionais também mostraram-se bastante diversificadas, sendo que dos 200 respondentes, 167 informaram a sua ocupação: 45 estudantes, 22 servidores públicos, 17 atendentes/vendedores, 14 empresários, 10 professores, 8 agricultores, 7 secretárias, 7 auxiliares administrativos, 6 técnicos em eletrônica, 5 cabeleireiras, 4 bancários, 2 domésticas, 2 gerentes comerciais, 2 mecânicos, 2 jornalistas, 2 contadores, 2 engenheiros civis, 1 técnico em radiologia, 1 farmacêutica, 1 corretor de imóveis, 1 corretor de seguros, 1 metalúrgico, 1 massoterapeuta, 1 borracheiro, 1 vereador e 1 advogado.

Em relação ao sexo dos entrevistados, $57 \%$ são do sexo feminino e $43 \%$, masculino. Já em relação à idade, a amostra caracteriza-se com uma predominância feminina e jovem, com $57 \%$ de mulheres e $51 \%$ situando-se na faixa entre de 18 e 28 anos. Vale destacar ainda, que $82 \%$ situa-se entre 18 e 40 anos.

Sobre a renda, $69 \%$ dos respondentes possuem a renda que varia entre um e dois salários mínimos (34\% até uma salário mínimo e $35 \%$ até dois salários mínimos). Apenas $6 \%$ possui a renda mais elevada indicada pela pesquisa, de mais de 8 salários mínimos.

O grau de escolaridade, embora variado mostrou uma predominância no nível superior, com $42 \%$ dos respondentes, seguido por Ensino médio completo com 39\%, Especialização/MBA com 10\%, Mestrado com $6 \%$ e Doutorado com $2 \%$.

Caracterizados os respondentes, passa-se então à apresentação dos resultados obtidos com a realização da pesquisa. Como já explicitado, os respondentes poderiam escolher sobre qual a dimensão gostariam de 


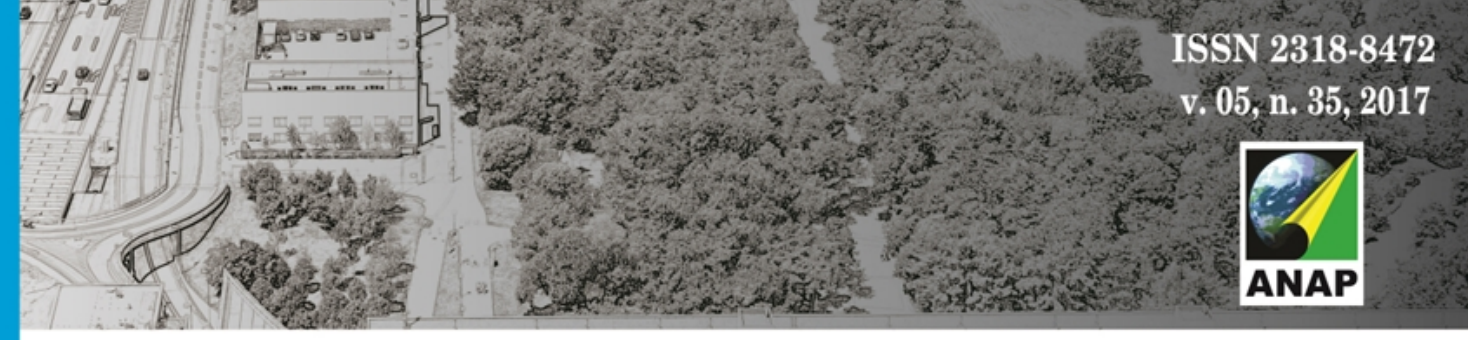

Gerenciamento de Cidades

responder, podendo ser apenas uma, ou mais de uma, conforme o papel desempenhado pelo respondente no município. Cada respondente, para cada dimensão escolhida apontou 5 características que julga-se prioritária para uma cidade de bem viver, ou bem estudar, ou bem trabalhar, ou bem investir ou bem visitar. Importante ressaltar que os resultados da investigação apontam que os atributos considerados prioritários variam de acordo com o papel que cada respondente exerce na sociedade.

Em relação ao papel de moradores, 125 respondentes usaram tal classificação, e as cinco opções mais citadas podem ser visualizadas no gráfico 1. Além das cinco mais citadas, merecem destaque também as características: Praças, ruas e arborização e Lazer e entretenimento com 29 indicações; Limpeza urbana, com 27 indicações; Escolas e universidades de qualidade, com 25; Boas vias de acesso, com 24 e em 10 lugar, Habitação e moradia com 22 indicações.

Importante ressaltar também, conforme apresentado na tabela 2, que na dimensão morador, todas as 30 opções de características foram selecionadas, obviamente, em maior ou menor intensidade, o que de certa forma, pode demonstrar que são todas importantes para uma cidade de bem viver.

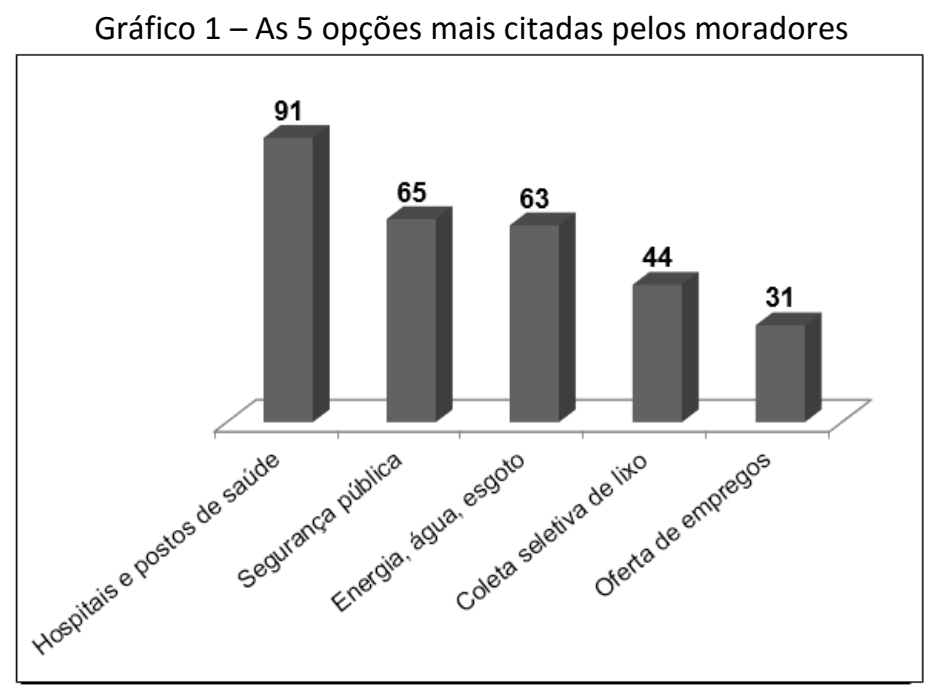

Fonte: Elaborado pelas autoras

Na dimensão Estudantes, 125 respondentes optaram por esse papel, e as características prioritárias apontadas podem ser visualizadas no gráfico 2 . Além das cinco mais citadas, merecem destaque as características: Boas vias de acesso, Bibliotecas públicas e Livrarias com 32 indicações; Lazer e entretenimento com 25 indicações; Habitação e moradia com 21 indicações, conforme demonstradas na tabela 2. Essas opções indicadas pelos estudantes estão relacionadas, além da própria atividade de estudar, com o perfil de muitos estudantes da cidade, que residem em cidades próximas, mas estudam nas Universidades da cidade, ou que mudaram-se recentemente para a cidade para aqui estudar, por isso a valorização de boas vias de acesso, além de moradia e habitação. Todos os 22 residentes que indicaram estar na cidade há menos de 1 ano eram estudantes. 


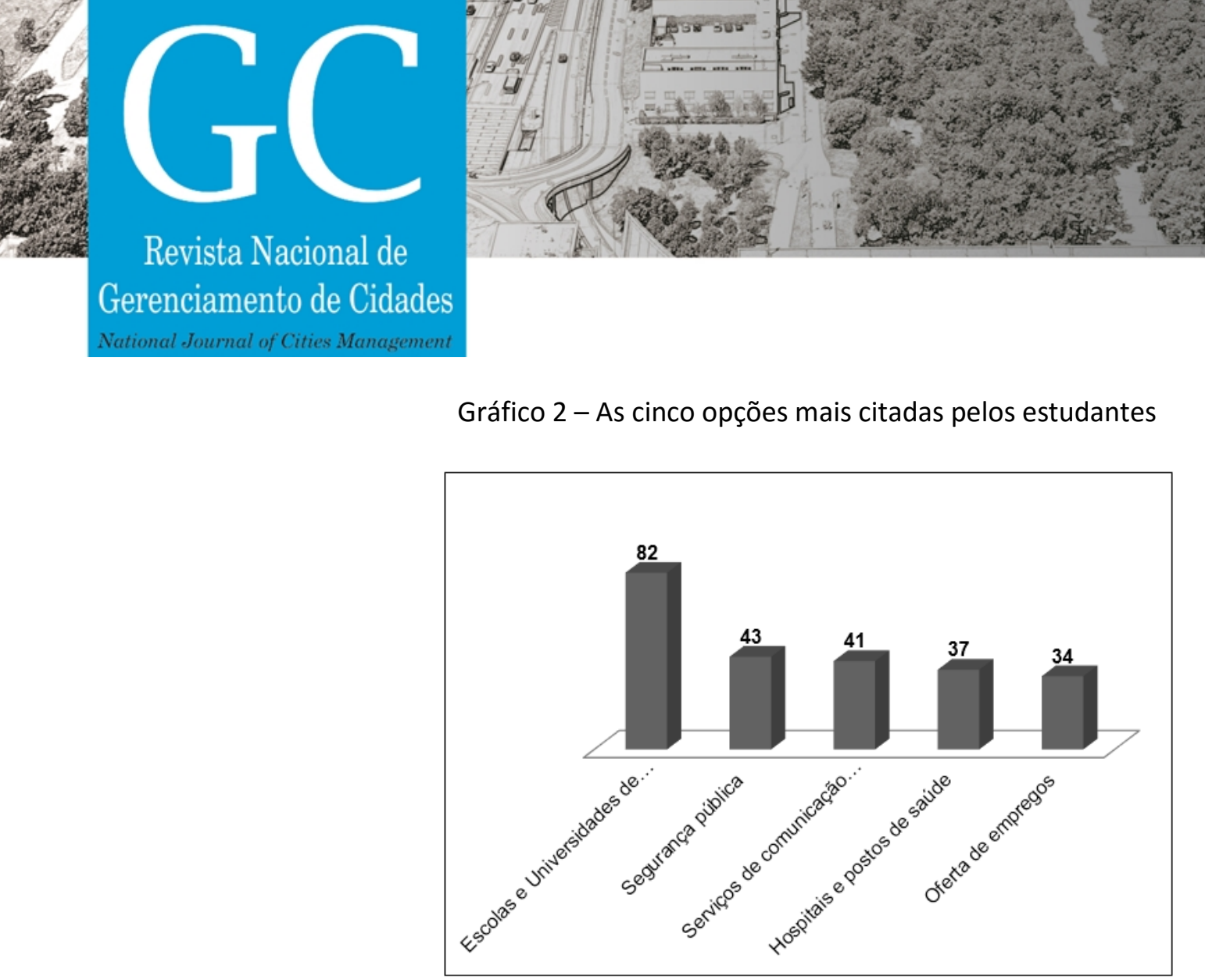

Fonte: Elaborado pelas autoras

Na dimensão de trabalhadores, 80 respondentes assumiram esse papel, apontando como prioritárias as características apresentadas no gráfico 3 . Além das 5 prioritárias, destacaram-se, para os trabalhadores, as características: Escolas e universidade de qualidade, com 21 indicações; Restaurantes com 18; Boas vias de acesso e Serviços de Comunicação eficientes (telefone e internet), ambas com 17 indicações; Energia, Água e Esgoto e Trânsito seguro com 16 indicações, conforme tabela 2.

Gráfico 3 - As cinco opções mais citadas por trabalhadores

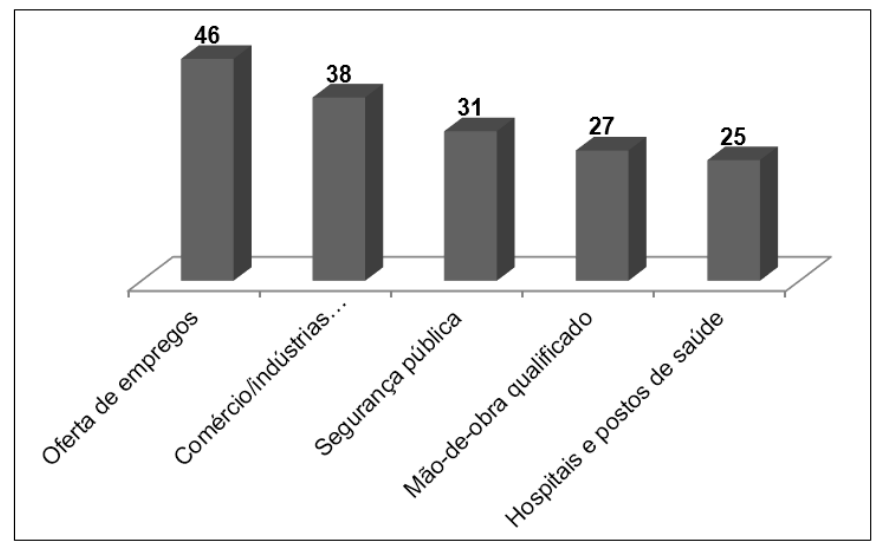

Fonte: Elaborado pelas autoras

Dentre os respondentes, 14 assumiram o papel de investidores na cidade de Cerro Largo, e as prioridades apontadas são apresentadas no gráfico 4. Além das cinco prioritárias destacam-se Limpeza Urbana com 5 


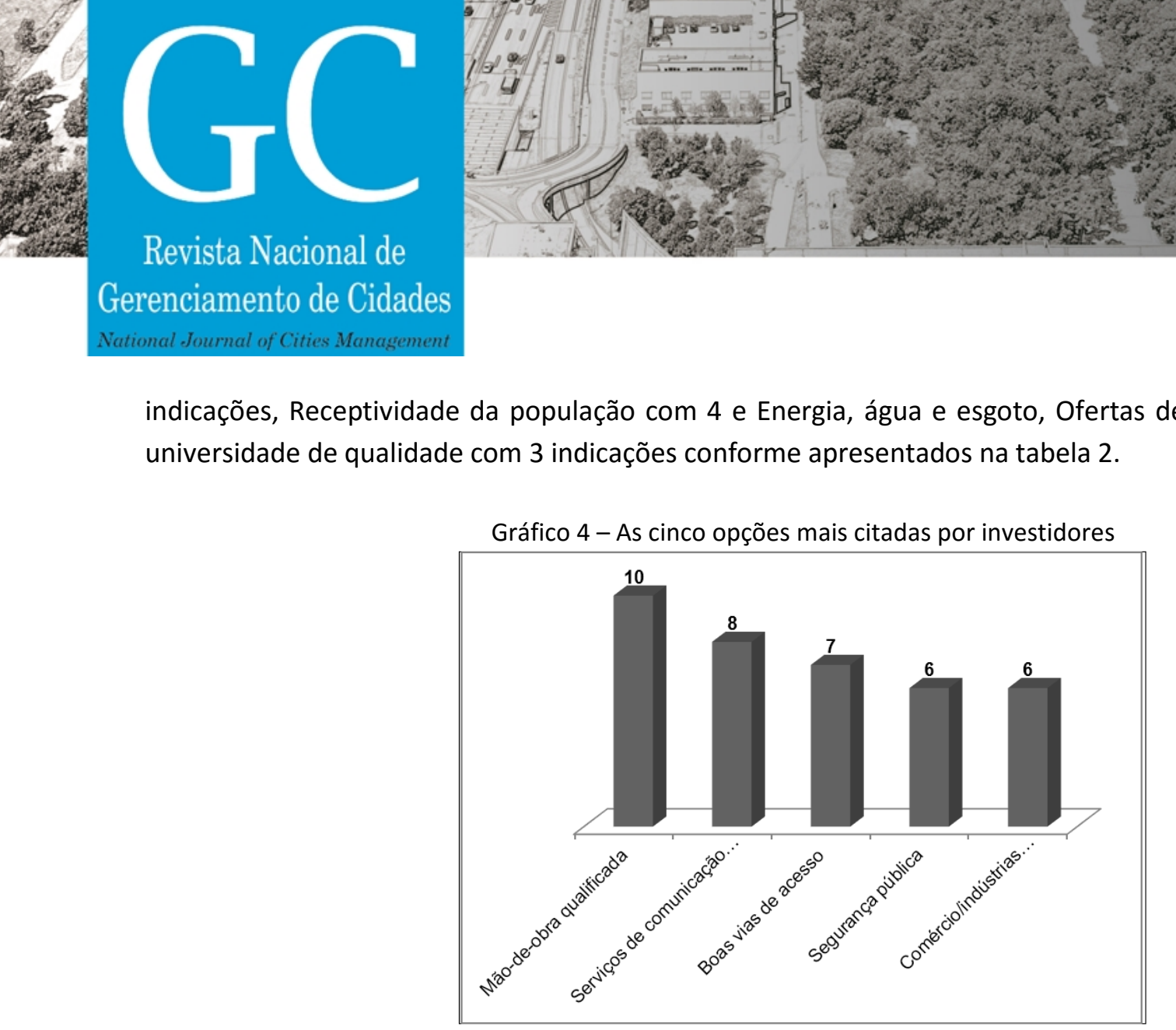

Revista Nacional de

indicações, Receptividade da população com 4 e Energia, água e esgoto, Ofertas de empregos e Escolas e universidade de qualidade com 3 indicações conforme apresentados na tabela 2.

Fonte: Elaborado pelas autoras

E em relação quinto público, visitantes, 16 pessoas responderam desempenhando esse papel social. As cinco prioritárias estão demonstradas no gráfico 7 , e para além dessas 5 , destacaram-se, conforme exposto na tabela 2: Limpeza urbana com 5, Hospitais e postos de saúde e Centro de cultura, lazer e esportes com 4 indicações; Praças, ruas e arborização e Escolas e universidade de qualidade, ambas com 3 indicações.

Gráfico 5 - As cinco opções mais citadas por visitantes

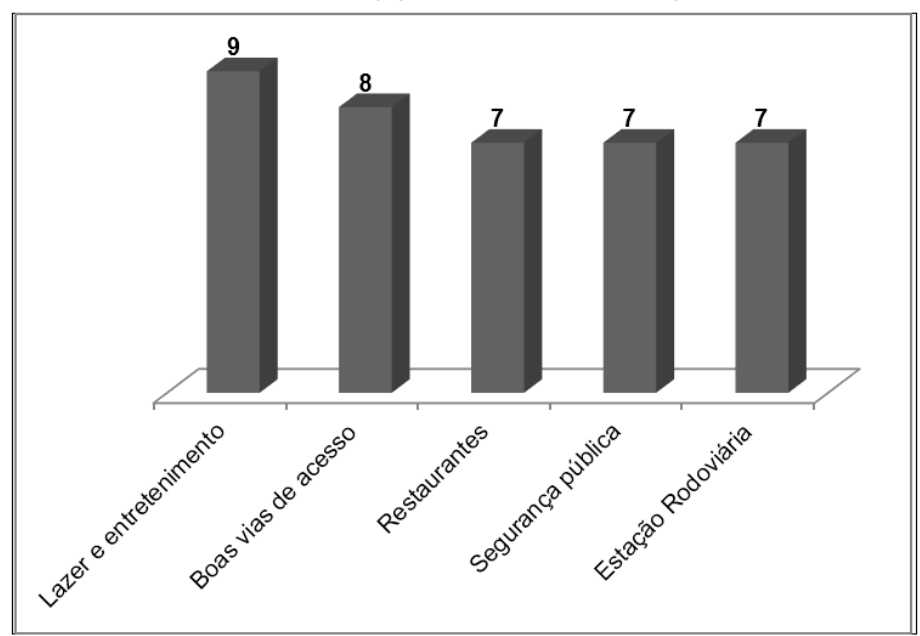

Fonte: Elaborado pelas autoras 


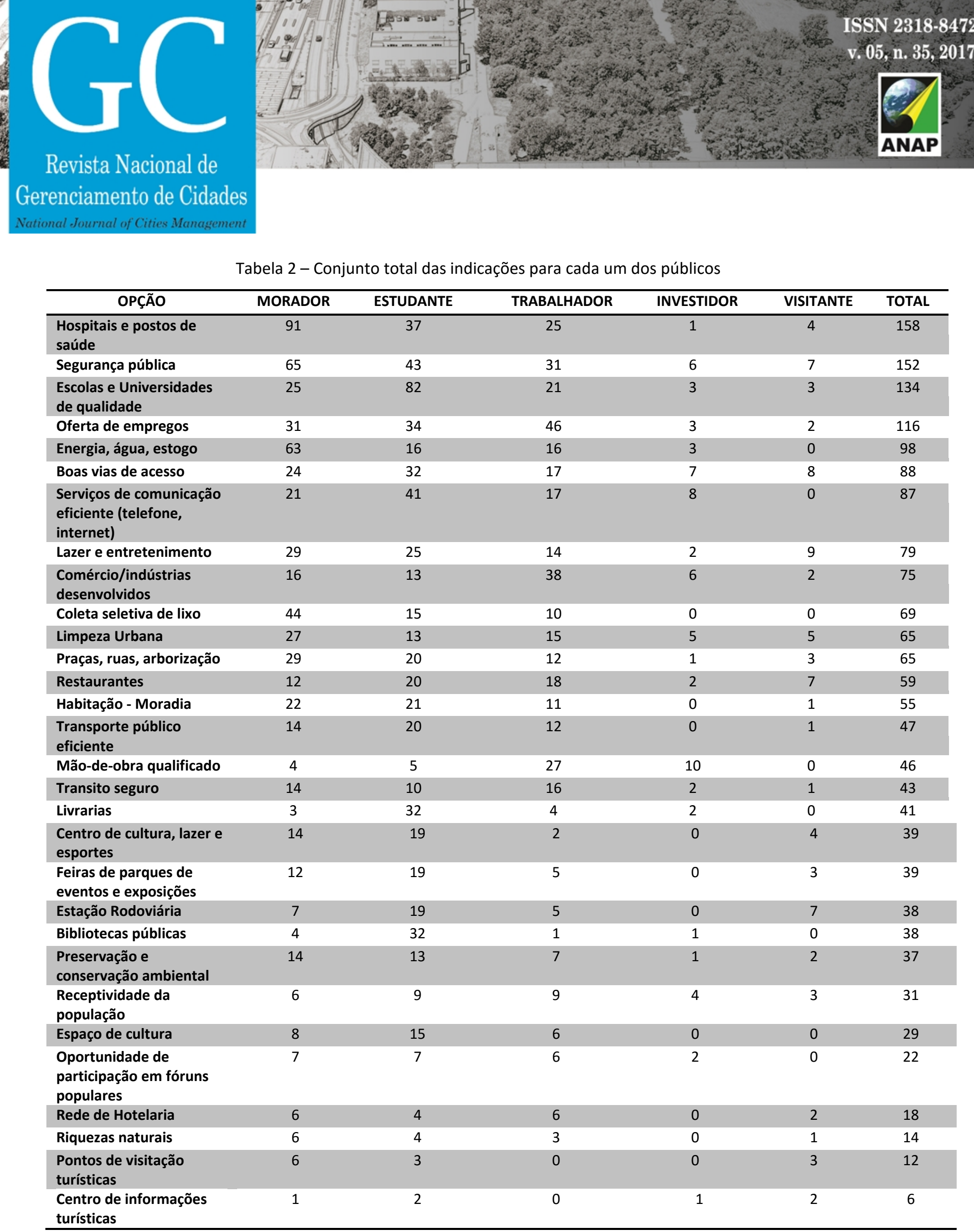

Fonte: Elaborado pelas autoras

Os resultados expostos nos gráficos 1, 2, 3, 4 e 5 e na tabela 2 evidenciam que alguns quesitos encontram-se presentes entre os cinco mais citados prioritários para mais de um papel, o que os torna ainda mais relevantes 


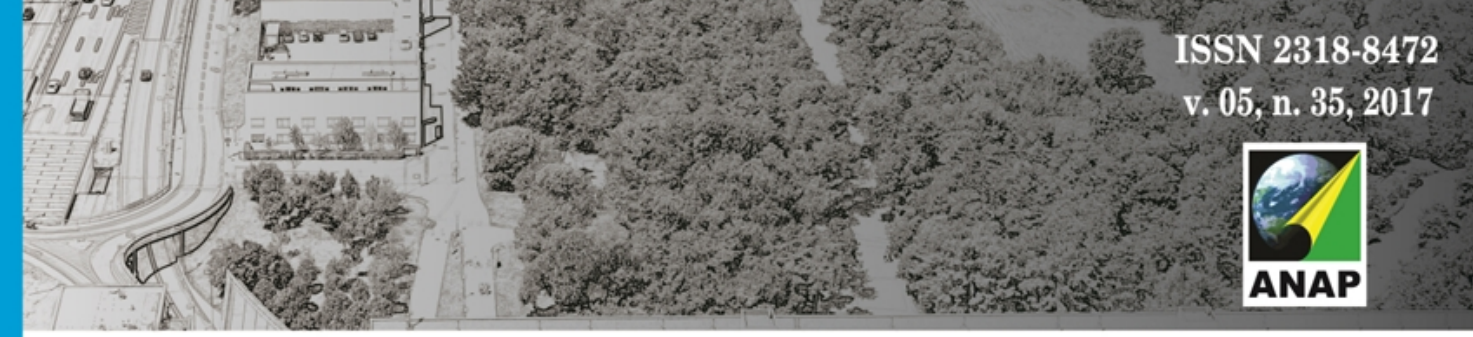

Gerenciamento de Cidades

e merecedores de atenção pelos planejadores públicos, para tornar uma cidade atrativa. São eles: Segurança Pública, que é apontado por todos os públicos como prioritária; Hospitais e Postos de Saúde e Oferta de empregos são apontado como prioridade em três grupos (moradores, estudantes e trabalhadores); Comércio e Indústria bem desenvolvidos é apontado como prioridade em dois grupos (trabalhadores e investidores); Mão de Obra qualificada é prioridade para dois grupos (trabalhadores e investidores); Boas vias de acesso é apontado em dois grupos (investidores e visitantes).

Outra análise possível, a partir da tabela 2, apontam algumas características que são mencionadas por todos os públicos, além da Segurança Pública: Boas vias de acesso, Hospitais e postos de saúde, Limpeza urbana, Praças, ruas e arborização, Preservação e Conservação ambiental, Trânsito seguro, Oferta de empregos, Escolas e universidades de qualidade, Comércio e indústria bem desenvolvidos, Lazer e entretenimento, Receptividade da população e Restaurantes.

$\mathrm{Na}$ análise anterior levou-se em consideração as percepções de cunho segmentado. Porém, vale a pena destacar, em termos absolutos as cinco percepções mais indicadas de forma geral: Hospital e postos de saúde com 158 indicações; Segurança pública com 152 indicações; Escolas e universidades de qualidade com 134; Oferta de empregos com 116 e Energia, água e esgoto com 98 indicações. Essa leitura de dados é bastante importante, caso o município opte por uma consideração geral acerca das percepções dos stakeholders do local, em lugar de uma ação visando algum público em específico.

Na última sessão do questionário, foi deixado um espaço para manifestações acerca de características, idéias ou manifestações que os respondentes julgassem pertinentes acerca do assunto. As manifestações estão transcritas no quadro 1. 
